\title{
A New Type of Energy Saving Construction Elevator
}

\author{
WeiPing OUYANG 1, a, GuoHua YUAN²,b and *Jun QIU1,c
}

\author{
1. Shanghai Institute of Special Equipment Inspection and Technical Research, Shanghai, China \\ 2. Baoshan District Institute of Special Equipment Supervision and Inspeciton, Shanghai, China \\ 'qiuj@ssei.cn \\ * Jun QIU
}

Keywords: energy saving, construction elevator, Niemann gear

Abstract: a new type of energy saving construction elevator which has optimized connecting form and adopted a new type of energy saving reducer employed the Niemann gear and new machining technology is introduced in the paper. The energy consumption test shows the efficiency of the new elevator is obviously better than conventional one, and performance at efficiency fluctuation and stability during the working time is much acceptable. In addition, the temperature rise of the bearing is lower for its reasonable structure, the relatively small and stable reducer operating current value ensure strong adaptability and less impact to power grid, and the failure rate of the components and parts is reduced therefore. The analysis shows the new elevator has excellent energy conservation property which has positive economic and social value.

\section{Preface}

The construction elevator is an indispensable and widely used mechanical equipment at the construction site, and responsible for vertical transport personnel and cargo work ${ }^{[1]}$. With the rapid development of elevator, the technology of structural dynamic analysis, finite element calculation model and optimization method, mechanical vibration and modal analysis, computer aided design and other advanced theory is applied to the research and development of the construction elevator.

The conventional elevator still exist some drawbacks, like vibration, low transmission efficiency, relatively low reliability, that need to be improved in the future. Through the analysis of design, manufacture, installation and debugging section of the standard section, driving device and cage structure of elevator, WenHao Wan and JianJun Wang ${ }^{[2,3]}$ determined the cause of the vibration and shaking of SC(D) serial construction elevator and some suggestions and methods were proposed correspondingly. YingSheng $\mathrm{He}^{[4]}$ found in his research that the main cause of elevator vibration is related to the meshing of gear rack, and suggest it could solve this problem through reducing vibration output, vibration transmission and curbing vibration diffusion. Based on the analysis of the structure and working principle of rack and pinion driven construction elevator, JianBing Li and his colleagues ${ }^{[5]}$ presumed that gear meshing, the roller manufacturing deviation, the uneven rotating speed and etc are closely related to the vibration of the driving mechanism. Some researcher also argue that the elevator efficiency is mainly determined by reducer efficiency, Juming Chen ${ }^{[6]}$ find the working efficiency of worm reducer is related to the reducer oil leakage, worm gear wear and transmission pinion abrasion. YingFeng Hou ${ }^{[7]}$ believe that profile modification tooth profile of the gear reducer can greatly improve the transmission efficiency, through the numerical analysis of the transmission efficiency of the reducer through MATLAB, the law of the influence of the number of teeth on the transmission efficiency and the selection principle of the number of occurrence are obtained. 
Due to the limitations of technology, manufacturing, cost and other issues, currently few manufacturers can complete optimization. A new energy-saving construction elevator is introduced in this paper, the structure and the power device of the elevator are optimized, the stability and the transmission efficiency of the elevator, therefore, are improved, the new elevator obviously has high economy and energy saving value, and conforms to the national energy saving and emission reduction and green environmental protection development plan.

\section{Energy Saving Construction Elevator}

The structure diagram of the energy saving construction elevator is shown at the Fig.1, compared with the conventional elevator, the main structure and reducer of the new one are optimized.

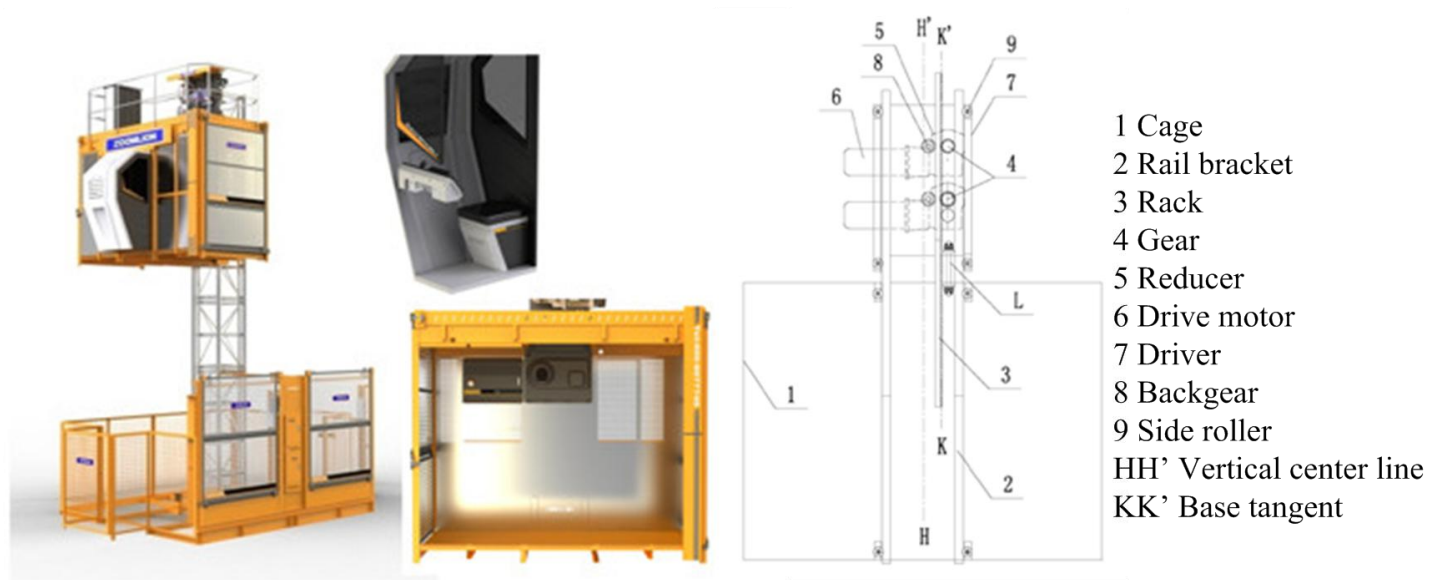

Fig. 1 structure diagram of the energy saving elevator

\section{Structure Optimization}

The commonly used construction elevator has three kinds of metal structure: double ear plate connection, elastic connecting rod and the middle- arranged rack. The double ear plate connection form need to ensure the drive gear drive system and lifting lug cage on the welding position accuracy, if there is any deviation from the position, the pin can not be installed and need to cut ear though re-welding, moreover, the poor interchangeability makes it difficult to swap with other cage. In order to ensure the installation, the rod of the elastic connecting rod form has a greater degree of freedom, the jitter phenomenon is more serious than the ear plate connection. For the middle-arranged rack one, though the meshing force is more optimal, the interchangeability of middle-arranged standard section still poor due to most standard section is bias.

As shown in the Fig.1, the main structure of the energy saving construction elevator including gear driving system and cage. The gear of the gear driving system is meshed with the rack which arranged vertically on the guide rail rack, and the lifting cage is lifted and moved along the guide frame through the hoisting point. The meshing normal line-KK' between the gears and racks is lateral offset when compared to the vertical centerline-KK' of the guide rail. Therefore, the center of gravity of the gear drive system is located at the transverse first side of the meshing normal line, the coupled lifting point are located on the transverse second sides of the common normal line. And the subtle location selection of the lifting point make the forward torque of the lifting point to the meshing normal line offset the reverse torque caused by the gravity of the gear drive system. The stress state of the meshing engagement is improved, and the abrasion of the gear, rack, back wheel 
and measuring roller relieved also, the operation process of the construction elevator become more stable and reliable therefore. In addition, the connection device between the driving frame and the cage is enhanced also, this make the driving frame can rotate freely around the $\mathrm{X}$ shaft and the $\mathrm{Y}$ shaft to the cage, thus, the cage vibration during the operation process become acceptable for the less vibration transmission of the driving mechanism in the left and right directions and the front and rear directions to the cage. The connecting device between driving support and cage is improved for energy saving elevator, with this connection the driving support can rotate freely along $\mathrm{X}$-axis and Y-axis, which make the vibration of cage become smaller. Through the structure optimization, the noise is becoming obviously lower when compared to the conventional one according to the GB/T 10054 noise measuring criterion, the noise within the cage is $78.1 \mathrm{db}$ and driving noise is $81 \mathrm{db}$.

\section{Reducer Optimization}

Some researchers argue that the gear profile optimization can improve the efficiency of reducer, the new type reducer is developed based on Niemann tooth modification and new machining technology. As it shown at the table 1, the bearing capacity of six head worm gear and oil film is strengthened for Niemann tooth modification and new machining technology. The driving efficiency is increasingly raised from $85 \%$ to $95 \%$, and the new reducer is easy to maintain and has long service life.

Table 1 parameters of Reducer

\begin{tabular}{|c|c|c|}
\hline parameter & Convention Reducer & $\begin{array}{c}\text { Energy saving } \\
\text { Reducer }\end{array}$ \\
\hline power & $11 \mathrm{KW}$ & $13 \mathrm{KW}$ \\
\hline driving efficiency & $80 \%$ & $95 \%$ \\
\hline oil volume & Turbine oil, 2.2L/each & Synthetic oil, 3L/each \\
\hline $\begin{array}{c}\text { Lubricating oil } \\
\text { replacement period }\end{array}$ & $\begin{array}{c}\text { Change 1 time/every 6 } \\
\text { months }\end{array}$ & $\begin{array}{c}\text { Change 1 time/every } 4 \\
\text { years }\end{array}$ \\
\hline $\begin{array}{c}\text { Direct benefit (in 8 } \\
\text { years of using period ) }\end{array}$ & $\begin{array}{c}\text { Need to be replaced 17 } \\
\text { times in life time }\end{array}$ & $\begin{array}{c}\text { Just need to be replaced } \\
1 \text { time in lifetime }\end{array}$ \\
\hline
\end{tabular}

\section{The Discussion of Test Result}

In order to further verify the performance of energy saving construction elevator, the new and conventional elevator were selected for comparative performance test, the main assessment parameter include: efficiency, bearing temperature rise and current situation of the operation.

\section{Efficiency Test}

The efficiency tests are carried out on the platform shown in Fig.2 to test the efficiency results between two elevators under different speeds and torques. 


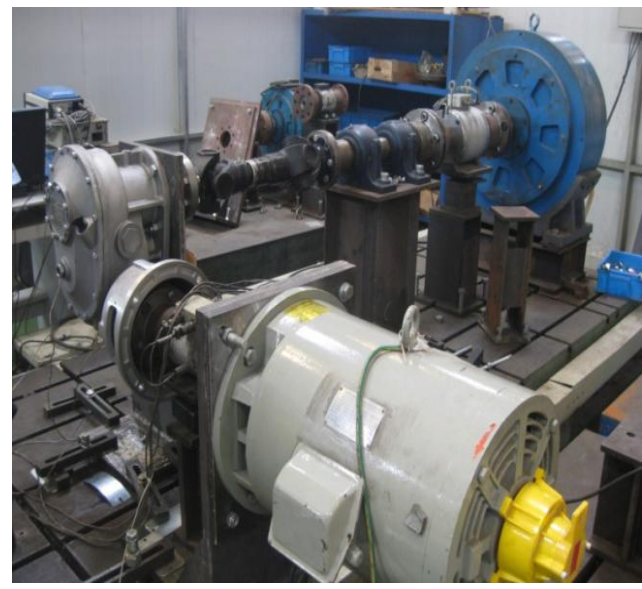

Fig. 2 efficiency test platform of reducer

The test results of the efficiency of the elevator under different speeds at $50 \mathrm{~Hz}$ are shown in Fig 3 , the efficiency of the new elevator is higher than that of the conventional one (especially under low rotate speed). The difference between two elevator decreases gradually with the increase of rotation rate, and the efficiency fluctuation of the new elevator is just $2 \%$ considerably lower to convention one.

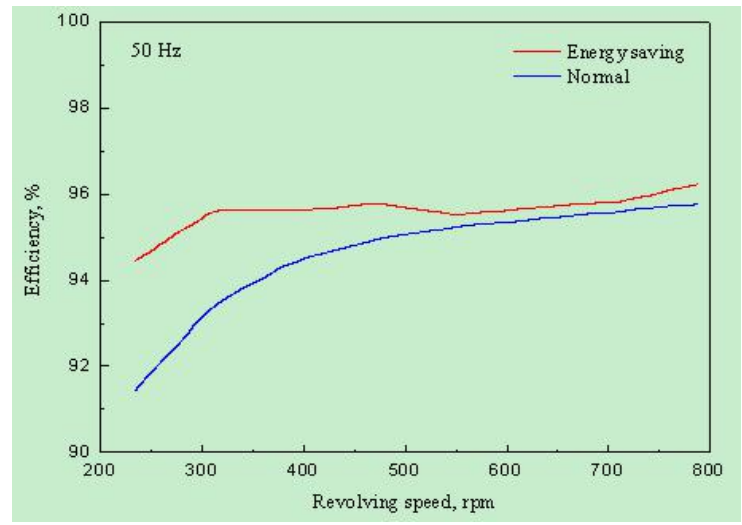

Fig. 3 efficiency test results between two elevators at different speeds

The efficiency test result between two elevators under different torque but same rotate seed (1400rpm) is shown at Fig.4. It can be seen from the Fig that the efficiency of the energy saving elevator is apparently higher than convention one under same rotate speed and torque. The max efficiency of the energy saving elevator is nearly $95 \%$ while conventional one is just $90 \%$.

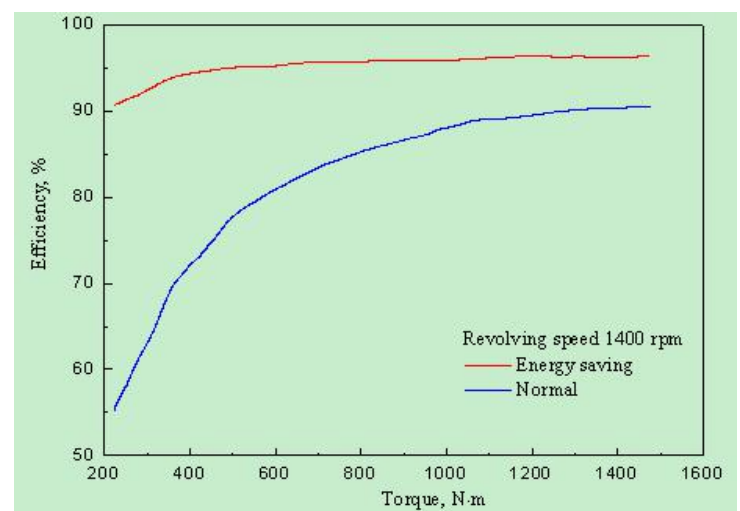

Fig. 4 efficiency test result between two elevators with different torque

It could be found from the test above that the efficiency of the new elevator is better to conventional one under certain frequency and constant speed, and the efficiency of the new one 
keeps above $90 \%$ in the whole process. The maximum $26 \mathrm{KW}$ will be enough for new elevator while $33 \mathrm{KW}$ is needed for convention one, $21000 \mathrm{KW}$ electricity will be saved for each elevator per year if the elevator works 5 hours everyday and 300 days each year, great social and economic benefits will produced and also conforms to national development requirements of energy saving and emission reduction.

\section{Temperature Rise Test}

The comparative temperature rise curve between two elevators under same rotate speed (1400rpm) and torque $(1530 \mathrm{Nm})$ is shown at the Fig.5. It can be seen from the picture that the temperature rise is significantly lower than the conventional one, and energy saving reducer can reduce the loss, improve efficiency effectively.

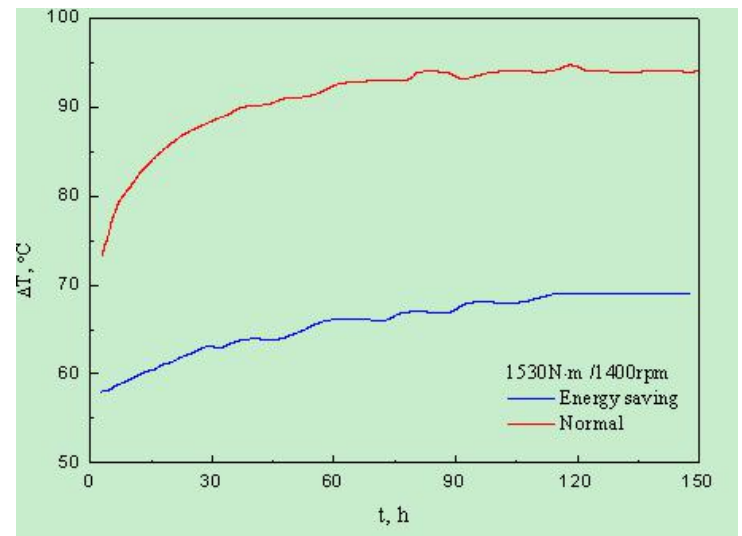

Fig. 5 temperature rise test between two elevator

\section{The Current Test}

The electric current test result is shown as Fig.6 and Fig.7 when two kinds of elevators are working with no load and full load.

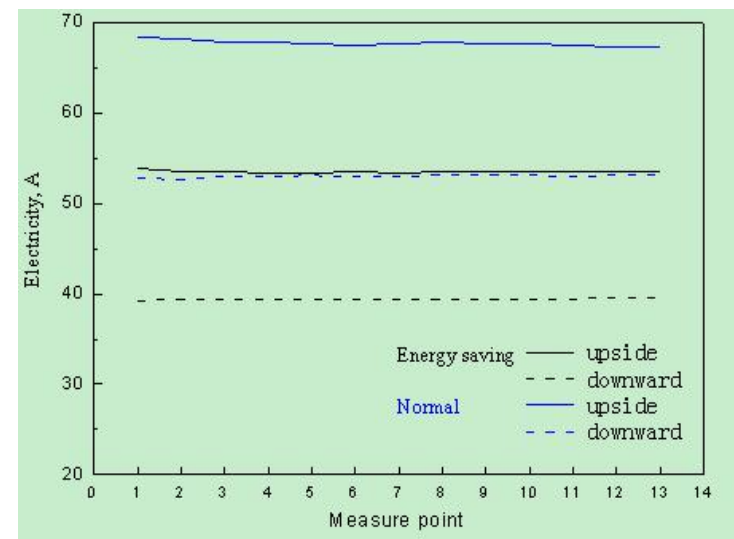

Fig. 6 no load current test result for two elevators

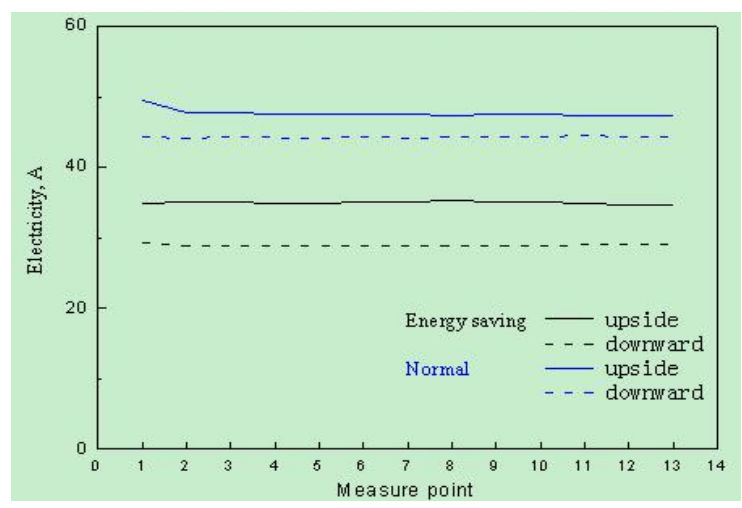

Fig. 7 full load current for two elevators 
Table 2 current test result of two elevators

\begin{tabular}{cccc}
\hline Type & Stroke & $\begin{array}{c}\text { Average } \\
\text { current }\end{array}$ & $\begin{array}{c}\text { Average } \\
\text { Variance }\end{array}$ \\
\hline \multirow{3}{*}{ Energy } & Up, no load & 34.95923 & 0.211168 \\
Saving & Down, no load & 28.91538 & 0.149544 \\
& Up, full load & 53.50538 & 0.12463 \\
& Down, full load & 39.42769 & 0,0717 \\
\hline \multirow{3}{*}{ Convention } & Up, no load & 47.67462 & 0.541289 \\
& Down, no load & 44.30231 & 0.139899 \\
& Up, full load & 67.74692 & 0.279736 \\
& Down, full load & 53.04308 & 0.157792 \\
\hline
\end{tabular}

The table 2 shows average current of energy saving elevator is lower than convention elevator, also the current is more stable than conventional elevator under different working condition. Especial under working condition of full load, its impact force on power grid and electric components is smaller because of lower current, also it has lower failure rate for electric components.

\section{Conclusion}

A new energy saving construction elevator is introduced in this paper, its efficiency is obvious higher when compared with the conventional one, the main conclusions are as follows:

1. The noise and vibration of structure can be reduced effectively by changing lifting point and improving connecting device between driving frame and cage. The maintaining cost and difficulty is reduced and the stability of elevator is increased by using energy saving elevator.

2. The efficiency of energy saving elevator is obviously higher than that of the conventional elevator, while the energy saving temperature rise is obviously lower than the conventional elevator whether under constant frequency or rotating rate.

3. For the lower and stable average current value of the new elevator, it brings less impact to the power grid especially under full-load condition. The small impact to the electronic control components and low failure rate of the electronic makes the energy saving construction elevator has satisfying adaptability therefore.

\section{Reference}

[1] Qihao Yu. The Development of Domestic Construction Elevator. Journal of Beijing Institute of Civil Engineering and Architecture. 2005, 21(4): 35-37.

[2] WenHao Wan. The Analysis and Improvement Methods of Y Vibration and Shaking of The Construction Elevator. Mechanical and electrical technology. 2012(03): 157-158.

[3] JianJun Wang, DeGang Cui. The Analysis of Vibration Noise of Construction Elevator During Operation Process. Construction mechanization. 2014(04): 54-55.

[4] YinSheng He, Wei Wang. The Cause Analysis and Solution of the Cage Vibration of The Construction hoist. Construction mechanization. 2013(03): 82-85.

[5] JianBin Li, LongXiang Zhu. The Vibration Analysis and Prevention Measures of The Construction Elevator Driving Device. Mechanical Research and Application. 2010(05): 131-132. [6] JiMing Chen, ChengMing Lu, QiFeng Chen. The Research on the efficiency of worm gear 
reducer. Inner Mongolia Science Technology and Economy. 2016(12): 96.

[7] YingFeng Hou, QingJiu Huang, Bin Chen. The Study on Efficiency of The 3Z Modified Profile Cycloid Gear Reducer. Mechanical Design and Manufacturing. 2015(09): 121-124. 